o texto prepara a análise desenvolvida no segundo subitem "A geopolítica de 'globalização' na década de 1980". Um parágrafo (p.142) resume os objetivos deste capítulo: "Neste trabalho analisam-se três temas, necessários para uma compreensão dos problemas enfrentados na indústria automobilística brasileira e particularmente nos segmentos sediados no município de São Bernardo do Campo. Em primeiro lugar a globalização da produção; em segundo lugar as aplicações de modernização tecnológica com novos modos de organização do trabalho; e em terceiro lugar as inovações nas relações empresariais e nas relações empresa/governo".

Estes três temas estão presentes de uma forma ou outra nos cinco textos escolhidos para o livro objeto desta resenha e, mesmo sendo tratados em épocas e países diferentes, explicitam as preocupações e as linhas de pesquisa do colega e amigo Phil, cujos resultados fazem parte do grande legado que nos deixou.

\section{VIVER EM RISCO - SOBRE A VULNERABILIDADE SOCIOECONÔMICA E CIVIL}

Lúcio Kowarick

São Paulo: Editora 34, 2009

\section{Cibele Saliba Rizek}

Profa. livre docente do Depto. de Arquitetura e Urbanismo da USP/São Carlos e pesquisadora do CNPq

Este livro se dedica a descrever e analisar a vulnerabilidade ou, mais precisamente, as vulnerabilidades que caracterizam as condiçōes de vida da população pobre da maior cidade brasileira. Produzido a partir de uma longa trajetória de pesquisa e reflexão, é uma fonte preciosa de informações, mas também de questōes que se repõem a cada capítulo, nos quais se ancoram conceitos e dimensōes teóricas como matrizes que podem e devem ser interrogadas, merecer contrapontos, passar pelo crivo dos processos e das dinâmicas observadas e, assim, em confronto com o presente, passar por atualizaçôes. São velhas e novas questões relativas à heterogeneidade da pobreza urbana, da população vulnerável, nomeada e observada de perto por meio das situações de moradia precária - cortiços na área central, periferias autoconstruídas e favelas.
Lúcio Kowarick, como se sabe, tem um lugar único por sua longa e fértil trajetória na pesquisa e na elucidação dos enigmas urbanos brasileiros. Não é demais lembrar, entre outros títulos, São Paulo - 1975. Crescimento e pobreza (Camargo, C. P. F.; Cardoso, F. H.; Kowarick, L. et al., São Paulo, Edições Loyola, 1976), A espoliação urbana (São Paulo, Editora Paz e Terra, 1980) ou Escritos urbanos (São Paulo, Editora 34, 2000), em que algumas das questóes presentes em Viver em Risco já estavam se desenhando. Mas se Escritos urbanos apontam temas e desdobramentos cujos pontos de inflexão constituem uma coletânea de ensaios sobre os temas então emergentes, na virada do milênio, Viver em risco traz um novo panorama. Parte dos achados do livro é resultante de incursões etnográficas que fornecem os elementos e informaçôes analisados a partir de uma ancoragem histórica, assim como de uma visão sociológica construída, inclusive, com base em informaçôes estatísticas secundárias. Este cruzamento de fontes de pesquisa permitem que as três situações urbanas - cortiços, favelas e periferias - ofereçam, com a ajuda das fotografias de Antonio Saggese, um quadro muito preciso do que significa viver em risco na São Paulo de nossos dias.

Se as etnografias são inéditas, parecem instigar também novas incursões no debate sobre as vulnerabilidades e a pobreza, novas proposições para duas articulações teórico-conceituais - a norte-americana e a francesa - como horizontes que propõem ângulos de visão e formas de inserção e de diálogo entre a produção acadêmica, a ordenação social e as proposições políticas. Os ecos e ressonâncias destes contrapontos também se fazem sentir na produção brasileira, quer graças a essas literaturas e à sua utilização em pesquisas e investigações empíricas, teses e dissertaçōes, publicaçōes, quer porque, imersas em nossas especificidades, as questōes relativas ao vínculo entre produção acadêmica, ordenação social e proposições políticas tenham passado por redefinições e inflexões nesse último decênio, o que também redesenhou legitimidades, constituiu novos consensos ou novos modos de encapsulamento e isolamento da reflexão sobre as cidades, para além das práticas e dos modos mais ou menos imediatos de gestão urbana. Assim, o livro recoloca os dois grandes feixes de leitura da pobreza urbana e de suas vulnerabilidades, tal como se se redefiniram depois do esgotamento das sociedades salariais constituí- 
das ou imaginadas como horizonte a ser alcançado: a discussão americana, pautada pela individualização e pela ótica da culpabilização das vítimas, mais ou menos moduladas pelo debate entre conservadores e liberais; e, por outro lado, a discussão francesa em torno da responsabilização do Estado pelas formas da "exclusão" e pelo seu combate, contra o que se identificou como fratura social ou desfiliação. Uma ascensão conservadora em torno das responsabilidades individuais como contraponto ao Estado do bem-estar, por um lado - o que de resto se comprova nas dificuldades recentes em alterar o sistema de saúde pública nos EUA -, e, por outro, a forte tradição republicana apoiada nas virtudes cívicas e na solidariedade em torno do Estado como elemento central, também bastante alquebrada e questionada pelo governo Sarkozy, entre outros, na França, demonstram a importância estratégica desse debate. Apontam também para um embate entre perspectivas distintas e ao mesmo tempo distanciadas das matrizes explicativas da vulnerabilidade socioeconômica e civil na sociedade brasileira e na cidade de São Paulo, em particular.

A vulnerabilidade brasileira e paulistana, analisada no Capítulo 2, nem se vincula estreitamente à matriz norte-americana, nem à francesa. Está emoldurada pela superação de um déficit de democracia política e pela longa e persistente permanência de um déficit de direitos civis e sociais. Lúcio Kowarick, na procura da caracterização de nossa especificidade, remonta o debate brasileiro, desde a questão da marginalidade e de seus desdobramentos e articulaçóes com a teoria da dependência, passando pelas críticas e desdobramentos em torno das questóes do chamado "desenvolvimento dependente", das formas de exclusão e inclusão perversa e funcional, instável e precária. Uma citação parece dar o tom dessa recuperação dos marcos teóricos em suas atualizaçōes brasileiras e latino-americanas: "se o socialismo saiu do horizonte dos ideais e das utopias e se, ademais, a ideia de revolução perdeu força mobilizadora porque, entre outras razões, como Saturno, ela tem devorado seus filhos, permanece o vasto fosso que caracteriza o apartheid social de nossas cidades" (p.75). Entre as "experiências de derrota" e a mentalidade de extermínio, as estratégias de evitação, a desconfiança e o medo como elementos estruturadores da sociabilidade, Lúcio Kowarick nos apresenta uma pergunta que desenha diálogos e confrontos entre perspectivas: "quais discursos e ações dão conteúdo às questões sociais de nossa atualidade urbana em torno da problemática da desigualdade e injustiça?" (p.95). Insatisfeito com as versões que explicam essa atualidade a partir de uma espécie de maldição de origem essencializada em um ethos de tristeza, cordialidade, miscigenação e conciliação, persegue as questóes de pesquisa a que se propôs enfrentar, em busca de algumas respostas e de novos desafios que tragam para o primeiro plano os modos de vida da população em situações de vulnerabilidade urbana, o que permite apreender um movimento pendular entre o reconhecimento de permanências e a constatação de sinais de transformação.

O primeiro feixe de questôes, itinerários e personagens se desenha a partir do centro da cidade de São Paulo e de seus cortiços. Nômades urbanos, andarilhos de lugar em lugar, de emprego em emprego, de cortiço em cortiço, em contiguidade com migrantes que constituíram famílias e se instalaram de modo um pouco mais estável em casas de cômodos, a questão da proximidade que caracteriza a moradia no centro ganha nitidez. Potencialidades e vulnerabilidades, políticas urbanas moldadas por diferentes concepções - que ora enfatizam a participação ora a delegação -, além das fotografias que flagram fluxos e situações da cidade, permitem que a experiência de seus moradores, flagrada em sua história, em suas dimensōes sociológicas e etnográficas, tomem corpo.

A periferia e as moradias autoconstruídas são objeto do capítulo seguinte, sua constituição como momento da história da cidade e como conformação territorial comparece acompanhada de seu duplo - a casa própria autoconstruída e seus significados. Ao gosto e de certo modo como uma necessidade da estrutura narrativa e de análise, o capítulo termina com um pergunta - vale a pena construir? - e muitas respostas complexas, difíceis, variáveis, "mas, na opinião daqueles que entraram neste espoliativo processo, no final das contas, por vários motivos, se chega a uma opinião favorável: apesar de todos os pesares" (p.219).

O Capítulo 5 discute a forma mais recente de moradia popular na cidade - as favelas. É preciso observar que favelas e periferias são lugares de algum estranhamento recíproco, ainda que se aproximem crescentemente, tanto territorialmente quanto como modos de inserção urbana. Alvo de políticas públicas e de intervençôes as mais variadas, portadoras de estigmas e 
objeto de violência simbólica e real, as favelas são a forma de moradia de algo como $8,7 \%$ da população da cidade. Entre urbanizações e remoções, entre ter e não ter direitos, ter e não ter a propriedade do terreno, esta população bastante heterogênea se equilibra, ora se estabelecendo, ora - quando possível -, desejando se mudar.

Nos três capítulos sobre as situações de moradia e de vulnerabilidade uma questão se faz presente, atravessando práticas, discursos e formas de um saber que nasce no solo dessas experiências. Trata-se das dimensões da violência, frequentemente agravadas pela imposição do silêncio, que modulam relações e modos de vida com seu crescimento. Na percepção de vulnerabilidades e de violências, na experiência do desrespeito e na denegação do reconhecimento e dos direitos, ganham corpo as heterogeneidades, as vantagens e desvantagens das situações de moradia e de inserção urbana daqueles que vivem em risco, que vivem na corda bamba na maior e mais rica cidade brasileira. Uma última referência dá concretude ao título deste livro indispensável para quem deseja conhecer as quebradas, a viração, os modos de morar das classes populares da cidade de São Paulo: em todas as situaçóes de pesquisa (loteamentos, favela e cortiços), "os entrevistados conhecem o local onde estão os bandidos... tiveram parentes próximos assassinados, viram pessoas mortas pelas ruas e todos sabem onde se localizam os traficantes... Também as crianças não são poupadas, pois se falasse o assassino 'vinha me pegar', diz o menino de sete anos (...) são trabalhadores que evitam e temem a presença de criminosos, pois sabem do perigo de ser atingido pelas balas ou ser confundido pelo arbítrio da ação policial: a sensação de 'viver em risco' é algo arraigado no cotidiano das pessoas, principalmente nos locais ermos, mal iluminados, onde a política só chega depois do crime" (p.297). Depois de descrever este viver em risco, como alguém que acompanhou e analisou os movimentos sociais da cidade, Kowarick conclui seu livro com um aceno menos sombrio: "É de esperar que a 'experiência do desrespeito'... venha a se constituir na matéria-prima de resistência e lutas coletivas que façam os grupos escanteados escaparem da vulnerabilidade socioeconômica e civil que caracteriza o cotidiano de suas existências" (p.301). Talvez o tom de aposta traga uma esperança e um quê de nostalgia de um autor fiel aos temas e questóes que brotam da experiência social na cidade e da cidade de São Paulo. 